\title{
Explaining motivation to represent: how does descriptive representation lead to substantive representation of racial and ethnic minorities?
}

DOI:

10.1080/01402382.2018.1455408

\section{Document Version}

Accepted author manuscript

Link to publication record in Manchester Research Explorer

Citation for published version (APA):

Sobolewska, M., Mckee, R., \& Campbell, R. (2018). Explaining motivation to represent: how does descriptive representation lead to substantive representation of racial and ethnic minorities? West European Politics, 41(6), 1237-1261. https://doi.org/10.1080/01402382.2018.1455408

Published in:

West European Politics

\section{Citing this paper}

Please note that where the full-text provided on Manchester Research Explorer is the Author Accepted Manuscript or Proof version this may differ from the final Published version. If citing, it is advised that you check and use the publisher's definitive version.

\section{General rights}

Copyright and moral rights for the publications made accessible in the Research Explorer are retained by the authors and/or other copyright owners and it is a condition of accessing publications that users recognise and abide by the legal requirements associated with these rights.

\section{Takedown policy}

If you believe that this document breaches copyright please refer to the University of Manchester's Takedown Procedures [http://man.ac.uk/04Y6Bo] or contact uml.scholarlycommunications@manchester.ac.uk providing relevant details, so we can investigate your claim.

\section{OPEN ACCESS}




\title{
Explaining motivation to represent: how does descriptive representation lead to substantive representation of racial and ethnic minorities?
}

Maria Sobolewska (University of Manchester)

Rebecca McKee (University College London)

Rosie Campbell (Birkbeck University of London)

Accepted for publication at West European Politics

\begin{abstract}
Empirical studies show a link between substantive and descriptive representation of racial and ethnic minorities. However, our understanding of the mechanisms through which this association operates comes almost exclusively from normative arguments. This paper examines three of these proposed mechanisms: two intrinsic mechanisms operationalized as perceptions of shared experience and a motivation to represent, and an extrinsic mechanism of electoral incentives. By doing so it moves on from documenting the link between descriptive and substantive representation, to explaining it. We find clear evidence that prospective minority representatives are influenced by all three motivations, to a different extent, with a difference between minority candidates of different parties. Also, while ethnic minority population of the constituency is usually associated with extrinsic motivation, we find it increases intrinsic motivation for minority representation among prospective minority representatives, suggesting these may be less distinct than it is assumed in the normative literature.
\end{abstract}

Keywords: descriptive representation; substantive representation; parliamentary candidates; ethnic minorities; racial minorities 
The claim that, in certain circumstances, descriptive representation is linked to the substantive representation of historically excluded groups has been subject to empirical testing and generally supported (Miller and Stokes 1963; Swain 1993; Bratton and Haynie 1999, Tate 2003; Preuhs 2006; Burden 2007; Minta 2009; Butler and Broockman 2011; Saalfeld and Bischof 2012; Chaney 2015). As this contemporary literature does not simplistically claim that 'any woman, black or Latino' representative will engage in substantive representation, there is increasingly a need for a systematic inquiry to understand under what conditions and circumstances they will (Mansbridge 1999; Dovi 2002). The assumption of a link between descriptive and substantive representation often rests on the supposition that legislators are able, or indeed motivated, to act for those individuals who share their politically salient characteristics. However, it is clearly possible that minority representatives who advance minority interests may not necessarily do so because they are intrinsically motivated; they may also act for extrinsic reasons, such as presumed electoral rewards from ethnic minority constituents.

Despite these mechanisms gaining recognition, existing empirical research has struggled to disentangle and thus properly test the different possibilities. The majority of studies focus on the USA, which, while being one of the most salient settings for struggles for racial minority representation, presents an empirical difficulty. In the USA it is almost impossible to differentiate between intrinsic and extrinsic motivations for black legislators using observational data because most black legislators represent minoritymajority districts (Lublin 1999), something which is no longer the case in the UK (Sobolewska 2013). This issue of identification creates another empirical difficulty, that of direct measurement of motivations. The existing studies employ primarily indirect measures, using the distribution of representative outcomes, rather than more direct attitudinal measures, as proxies for intrinsic and extrinsic motivation (Butler and 
Broockman 2011; Sallfeld and Bischof 2012). Using a 2015 survey of parliamentary candidates (van Heerde-Hudson and Campbell 2015), containing attitudinal measures, our analysis differentiates between the two possible mechanisms of intrinsic motivation proposed in the theoretical literature; firstly, a sense of shared experience of racial prejudice and discrimination, and secondly, the sense of responsibility to represent minority voters. We can also assess what role electoral incentives play in the distribution of these attitudes, thus elaborating on whether representing minority voters in districts with a large proportion of ethnic minorities truly reflects a simple extrinsic motivation to represent, or in fact increases the intrinsic motivation to do so, through changing representatives' attitudes. Similarly, although the role of party affiliation and ideology has been shown to have an effect on the link between descriptive and substantive representation (Preuhs 2006; Saalfeld et al. 2011), this is also difficult to explore in the US context, as the majority of black legislators are Democrats. Again, in Britain, this is not the case with an almost even split between the two main parties in terms of ethnic diversity ${ }^{1}$.

We find clear evidence for the proposed intrinsic mechanisms linking descriptive and substantive representation: minority candidates share a sense of common minority experiences, and feel a responsibility to represent minority voters, although this is

\footnotetext{
${ }^{1}$ In the UK $41 \%$ of ethnic minority MPs are Conservative, 56\% Labour. A similar even distribution is present in the candidate survey we use: see the data section for details. Both parties have more South Asian MPs and candidates than black African and black Caribbean ones (see Sobolewska 2014). In fact the only anomaly in the data is lack of any Labour candidates from these groups; this is despite the much greater support for Labour from these ethnic minority groups. Ethnic minority is defined, as is usually the case in the UK in studies of descriptive representation, as of non-white origin (for an exception to this see Sobolewska 2016).
} 
moderated by political party. Left and liberal parties' minority candidates are more intrinsically motivated to represent minorities. Additionally, the traditional indicator of extrinsic motivation, electoral incentives engendered by an ethnically diverse electorate, can work through increasing prospective representatives' intrinsic motivation. Those minority candidates standing in more ethnically diverse seats were more motivated than the ones standing in predominantly white seats.

\section{THEORETICAL MECHANISMS FOR SUBSTANTIVE REPRESENTATION}

The potential mechanisms underlying a link between descriptive and substantive representation are empirically under-researched but not under-theorised. There is a large body of literature seeking to discern these mechanisms. Those that are dominant in the literature are: a sense of shared experience, a motivation to represent and, electoral incentives. These have deep roots in the theoretical literature and imply both an intrinsic and extrinsic motivation to represent on the part of the descriptive representatives, although as we will contend later, what appear to be extrinsic electoral incentives may in fact lead to a change in levels of intrinsic motivation.

\section{Shared experience}

In the US literature, shared experience is understood as a core mechanism binding members of the disadvantaged group across other divides such as economic or social inequality (Mansbridge 1999), and acting as a motivation for representatives from these groups to engage in substantive representation. Racial and ethnic minorities have a sense of shared experience because of historical and contemporary discrimination and from experiencing political mobilisation to overcome their group disadvantages. Thus, their group membership affects the course and quality of their lives and is politicised. Shared 
experience is the most often quoted theoretical mechanism for why descriptive representatives would be best placed to represent traditionally under-represented voters. In the USA, much research has examined shared experience, both between members of the disempowered groups, and between them and their representatives (Swain 1993). However, in the UK, there is less research on this concept, although it has been shown to exist and influence political choices of ethnic minorities (Heath et al. 2013).

The difficulties in operationalizing shared experience between members of racial and ethnic minority groups and their representatives originate in the inherent difficulty of operationalizing any notion of shared experience between members of the same ethnic group (shared by the literature studying representation of women). First, experience is not homogenous among under-represented groups, especially among ethnic and racial minorities where it could be argued that there are no obvious commonalities, such as the realities of childbearing and child rearing shared by many women, but even for women, the assumption of commonality of experience is controversial (Celis 2012). To overcome this difficulty, this paper will not rely on the assumption of common experience, as is often done, nor attempt to measure those objectively using demographics, or socioeconomic status, but instead it will use the perception of commonality of experience, best captured by the notion of linked fate (Dawson 1994; Whitby 1997; Mansbridge 1999; Mansbridge 2003; Gay 2004; Burden 2007).

Linked fate accounts for more than a sense of group solidarity or identity and is the understanding that individual opportunities and life chances are intrinsically linked to the group as a whole (Dawson 1994; Gay and Tate 1998). It involves a sense of acute awareness that what happens to the group is also something that affects the individual within the group and is explicitly applied to racial and ethnic minorities, usually African Americans, but increasingly to other ethnic minority groups (Junn and Masuoka 2008). 
The concept is applied to these groups with distinct histories of discrimination and experiences of prejudice and is consistent with some of the aspects of the earlier concept of group consciousness (Miller et al. 1981) particularly the sense of injustice at the group's position and a systemic explanation of it, as opposed to individualistic explanations. These two cognitive elements of the concept are crucial, as they enable political mobilisation and expression of distinct interests, and are a prerequisite for conscious acts of substantive representation. Those descriptive representatives that share this sense of injustice and a particular set of explanations of the injustice can articulate group interests and attempt to form trust-based relationships with other members of the group (Dovi 2002); these two cognitive mechanisms can thus enable shared experience to translate into substantive representation.

Using the concept of linked fate to operationalize shared experience may also help resolve an issue of measurement. Since the basis of the concept (Dawson 1994) rests on a history of racial discrimination as the preferred systemic explanation for group-based injustice, the perception that non-white people are held back by prejudice and discrimination is used as a measure of shared experience. Although the experience of being held back by racial discrimination can only be meaningfully shared by non-white candidates, we also asked white candidates if they agreed non-white people are held back. The logic behind this is that the perception that their non-white constituents share common experiences of discrimination fulfils a similar cognitive role for white candidates as it does for minority prospective representatives: it enables them to recognise common political interests and a systemic - rather than individualistic- explanation for them, which can lead them to perceive a need to represent these interests substantively. A white representative who would not agree that their minority constituents share a common reality of prejudice is therefore less likely to represent their shared experience very much 
in parallel with minority representatives. Thus, while it is not implausible that white representatives perceive racial and ethnic minority groups as sharing distinct political agendas worth representing, we hypothesise that candidates directly originating from these minorities will have a stronger perception of these issues.

H1 Ethnic minority candidates support the statement that non-whites are held back by prejudice more than white candidates, indicating that they have a sense of shared experience with ethnic minority voters

\section{Motivation to represent}

The second most prominent theoretical mechanism linking substantive and descriptive representation is the greater willingness of ethnic minority representatives to represent ethnic minorities substantively. This is somewhat related to the idea of shared experience, and it may well be that feelings of solidarity and commonality among members of a group may foster a sense of duty to act for the group. However, they are conceptually distinct and correspond to two different mechanisms, proposed by Mansbridge (1999), through which substantive representation can happen. While shared experience can enable descriptive representatives to represent substantively in times where 'innovative thinking in contexts of uncrystallized [...] interests' is needed (Mansbridge 1999, p628), willingness to represent is necessary for communication with fellow members of one's descriptive group, particularly in cases where such communication is not contained within the usual relationship of representation of one's voters. This second mechanism has been indirectly confirmed by studies showcasing surrogate representation, where representatives respond to concerns of racial and ethnic minority voters residing outside of their own electoral district (Swain 1993; Broockman 2013). Since such representation 
requires a conscious expression of a desire to engage with fellow minorities regardless of their residency and specifically on the basis of their ethnicity, its existence has been interpreted as proof of representatives' intrinsic motivation to represent ${ }^{2}$.

Being able to ask about a motivation directly, and using a relatively larger and more diverse sample than has been possible to date, is therefore a rare opportunity to see if minority representatives' differential representational behaviours are backed up by a conscious realisation that, as descriptive representatives, they face the responsibility to engage in substantive representation. Measuring willingness to represent directly is clearly an improvement on using observable outcomes assuming that they are the result of a motivation to represent, especially as representatives are usually very limited in how many tangible outcomes such as policy changes they can actually achieve (Welch and Hibbing 1984; Meier et al. 2005; Saalfeld and Kyriakopoulou 2010).

Measuring representational attitudes, rather than outcomes, can also help in operationalizing the notoriously tricky concept of substantive representation. A successful operationalization of substantive representation would involve the development of objective measures of the group interests that are to be represented, about which there is no universal agreement (Dovi 2002). One way to overcome this problem is to focus on representative claims (Saward 2006; Saward 2010), rather than making judgements about the quality of outcomes of substantive representation. This approach shifts the focus on to what claims politicians make about who they think they are representing and thus, in our case, their attitudinal sense of willingness or duty to represent. This also sidesteps another issue of measurement, especially in the UK, which

\footnotetext{
${ }^{2}$ In Britain surrogate representation is effectively prevented by a parliamentary convention that MPs do not respond requests from those outside their parliamentary constituency.
} 
is the practical limitation of what MPs can do and say in parliament, given the constraints imposed by the party whips, party control over resources, and other legislative limitations (for a discussion see Saalfeld et al. 2011). Measuring the intention to represent through a sense of duty and responsibility to do so among parliamentary candidates captures the moment before the intervention of such confounding influences and limitations. These considerations lead to the second hypothesis;

$\mathrm{H}_{2}$ : Ethnic minority candidates will agree more strongly than white candidates that being an ethnic minority representative presents a responsibility to represent ethnic minority voters.

\section{Party ideology as moderator}

The reason that party ideology might moderate the relationship between descriptive and substantive representation can partly be explained by the parties' different histories of descriptive representation, with the majority of countries conforming to the pattern that left-leaning and liberal parties lead on descriptive representation of ethnic and racial minorities (Kittilson and Tate 2004; Bird et al 2010). In the US the lack of variance both in partisanship of representatives, but also in policy preferences of ethnic and racial minority voters, has led to many studies that measure substantive representation directly by whether the representatives roll-call vote records are liberal or conservative, thus equating left-leaning roll-call voting with minority substantive representation (Welch and Hibbing 1984; Casellas and Leal 2010).As we discussed earlier, in contemporary Britain both the Labour and Conservative parties are almost evenly matched on ethnic minority representation, enabling us to study variations by party more in depth.

The prevalence of systemic explanations of inequality over individualistic ones, usually associated with parties of the left, is particularly relevant to our conceptualisation 
of shared experience, and is likely to vary by party ideology along the left-right spectrum. In the UK, the Labour Party is traditionally the party associated with support for ethnic minorities, since the advent of post-war race and immigration politics (Norris et al. 1992). To date, Labour governments have passed all anti-discrimination legislation pertaining to race and ethnicity and the party has, until recently, commanded over 90 per cent support rates among ethnic minority voters (Heath et al. 2013). The Labour Party has formalised the incorporation of ethnic minority groups through a multicultural route, in which ethnic groups, and not individual voters, have become a basis of the party's engagement with minority communities (Garbaye 2008). This puts ethnicity, group experience of ethnicity, and group rights at the heart of Labour's approach to racial and ethnic difference. We also expect that, since the Labour Party has traditionally championed descriptive representation by electing ethnic minority representatives from the most ethnically diverse seats (Sobolewska 2013), the sense of motivation to represent will also be greater among Labour minority MPs.

Also leaning to the left on many issues, the Liberal Democrats are also ideologically multicultural in their approach to ethnic diversity. Although, in contrast to Labour, the Liberal Democrats have only had two minority MPs elected to date, this is usually blamed on this party's shortage of winnable seats (which also affects the party's female representation). The Liberal Democrats have however made many attempts to change this, as they became the first party to publish an ethnic minority manifesto, introduce ethnic balance on their shortlists for candidates, and the first to debate allminority shortlists (Sobolewska 2013). Therefore, while the party has seemingly a very bad record on descriptive representation, we expect that their attitudes towards representation might be more in line with Labour. We also include the Scottish National Party and the Green parties in the group of left-leaning parties with ideologies of 
multiculturalism, despite their recent emergence and limited success with electing minority MPs.

In contrast, the Conservative party has sought to win support from some segments of the ethnic minority population through a colour-blind approach (Sobolewska 2013). The best example was an electoral poster from the 1980s proclaiming 'Labour say he's black, Tories say he's British'. While this strategy failed to draw ethnic minority voters away from the Labour party, it illustrates the party's instincts on this issue that can easily be extended to perceptions of and actual political representation. The representative style of minority Conservative MPs seem to confirm this: for example Adam Afriyie, their first black African MP, in tune with Conservative ideology, has declared his opposition to positive discrimination, stating "The selection of candidates based on personal characteristics - that are arbitrary or merely in vogue - should not enjoy legal force if we believe in equality of opportunity" (Afriyie 2010). Although this trend reversed somewhat with the arrival of David Cameron as the Conservative Leader in 2005, whose objective of party modernisation included addressing the issues of race diversity and discrimination more openly (Sobolewska 2013), it is unlikely that the reversal has been complete in this short period of time, or that it has disseminated throughout the party.

Given the wide range of ethnic minority candidates, some of whom represent UKIP, a party thought by many to be racist or at least xenophobic (Ford et al. 2012), we expect that the relationship between the party affiliation of candidates may complicate the previously more straight forward relationship between ethnicity of candidates and representatives and their position on representation of ethnic minority interests. Since the vast majority of ethnic minority MPs in Britain (and elsewhere) have traditionally been elected by parties of the left, we posit that this may have driven the link between descriptive and substantive representation. However, given the normative mechanisms of 
representation, even minority candidates of the right-wing parties are expected to show some levels of shared experience and responsibility to represent. Against this background, we propose a two-step hypothesis: in that firstly party affiliation with a party of the left will work in the same direction as ethnicity making these candidates most motivated to represent; and then secondly, that even when party affiliation with a party of the right works in the opposite direction to ethnicity, minority candidates of parties on the right will still exceed their white colleagues' levels of agreement with our representational attitudes items.

H3.1 Minority candidates from left leaning parties will experience influences from both their ethnicity and left-wing ideology thus becoming most motivated to represent.

H3.2 Minority candidates of right wing parties will show a greater agreement with our representational attitudes than their non-minority right-wing colleagues, but less so than their left-wing peers.

\section{Electoral incentives}

Another proposed mechanism for explaining motivation to represent minorities substantively is a rational-choice mechanism, which, in contrast with the previously discussed intrinsic motivations, focuses on an extrinsic motivation. It emphasises the electoral calculus assumed to be behind the actions of vote-seeking representatives (Mansbridge 2003; Norris 2004) as they direct their finite resources to activities they believe will be most appealing to their constituents, with the aim of re-election. Thus, those in electoral districts with high concentration of racial and ethnic minorities may see representing minority voters as an effective means of re-election. Many studies find that representatives seek to show that they are responsive to their constituents, and many now 
report their parliamentary activity on their own websites, including listing questions they have raised. Even before the internet, Franklin and Norton reported that 82 per cent of British MPs said they would send reports of their parliamentary activity to the local press (Franklin and Norton 1993).

The electoral incentive proposed to drive representatives' behaviour is termed by Mansbridge (2003) as 'anticipatory' representation. Whereby representatives undertake activities, modifying their behaviour in a way that they believe voters will reward in the future. Consequently, representatives with a higher proportion of ethnic minorities in their district should be more responsive to them, expecting to be rewarded for it at election time. Although this effect has been hard to identify in the USA, due to the already mentioned effects of racial gerrymandering, some research found a relationship between the percentage ethnic minorities in the seat and representatives' voting behaviour (Welch and Hibbing 1984; Casellas and Leal 2010). In the UK Saalfeld and Bischof (2012), looked at parliamentary questions in the House of Commons and found that although minority representatives were more likely to raise ethnic issues in parliament, all MPs were responsive to the ethnic make-up of their constituencies.

However, although the conclusion that responsiveness to minority voters' interests in ethnically diverse seats constitutes an extrinsic motivation is both intuitively appealing and empirically sound, this is not necessarily the only possibility. The representative with a higher concentration of minority voters is more likely to hear from these voters. This makes it at least likely that the representative will be more responsive not out of electoral calculation, but due to preferential access to information about ethnic minority interests (Mansbridge 1999), which may in turn increase their level of concern with those interests. Although this paper cannot exclude the possibility that extrinsic motivation operates among prospective candidates, as our data lack information on any 
representative outcomes and thus make it impossible to test the direct impact of electoral calculus on substantive representation, it can address the theoretical mechanism that offers an alternative to the usually assumed direct link between the demographics of the electoral district and substantive representation.

The possibility, which we want to test here, is that the demographic make-up of the district might in fact work through increasing the representatives' levels of motivation to represent ethnic minority issues, and their perception of shared experience of minorities, both intrinsic motivators of representation. The process envisaged here is one of internalisation, rather than of calculated reasoning. As a result, we propose that the ethnic demographic make-up of the electoral districts may impact on the levels of intrinsic motivation to represent, a possibility that to our knowledge has not been tested empirically. Again, what we expect here, as in the case of party ideology, is a moderating effect.

H4.1 Both a sense that non-white people are held back by prejudice and a sense that ethnic candidates have a responsibility to represent minorities will be stronger among candidates contesting electoral districts with a large ethnic minority presence.

H4.2 For ethnic minority candidates this effect will be stronger.

\section{DATA AND METHODS}

We use an anonymous postal survey of parliamentary candidates contesting seats in 2015 UK elections, the Representative Audit of Britain (Campbell and Hudson 2015) to directly measure the levels and distribution of attitudes towards representation of British ethnic minorities. Ethnic minorities in Britain are defined as non-white by the Census ${ }^{3}$,

\footnotetext{
${ }^{3}$ https://www.ons.gov.uk/ons/guide-method/.../primary...questions/ethnic-group.pdf
} 
and predominantly fall within the broad groups of South Asian (from the Indian subcontinent), Caribbean Black, African Black and other smaller groups. The RAB ${ }^{4}$ survey includes 1,798 candidates who completed the survey from a total 3,174 candidates that stood for election; giving a response rate of 56.6\% (although some questions were not included in all versions of the questionnaire and thus have a lower response rate $^{5}$ ). Of the estimated 230 ethnic minority candidates standing,100responded to the survey (Lamprinakou et al. 2016), giving a response rate for minority candidates of $43.5 \%$. Although, it can be argued that a sample size of 100 is relatively small, it is a fairly balanced sample of minority candidates in terms of seats contested and party affiliation. Of the 100 ethnic minority candidates who responded to the survey, 19 were Conservatives, 20 Labour, 29 Liberal Democrats, 13 UKIP, 18 Green and 1 SNP. Further, 61 were men and 39 women, 5 were incumbent MPs, and 8 were subsequently elected as MPs in 2015. Thus, this data offers a reasonable spread, necessary for the purposes of this analysis.

In the RAB survey, all questions were asked to all candidates, regardless of race, providing the opportunity to compare ethnic minority and non-minority candidates' attitudes. Based on the theoretical literature discussed, the analysis includes two questions that can be used to measure to shared experience and willingness to represent ethnic minorities. For shared experience, respondents were asked how far they agreed that 'nonwhite people are held back by prejudice and discrimination' on a five-point scale from 'strongly agree' to 'strongly disagree'. Motivation to represent is measured by an item asking the respondent how much they agreed that 'being an ethnic minority candidate

\footnotetext{
${ }^{4}$ The survey was in the field between March 2015 and March 2016.

${ }^{5}$ The valid number of responses for the key variables in the analysis varies and is indicated in each table separately.
} 
presents a responsibility to represent minorities' on an 11-point scale, from 0 'it is not a responsibility' to 10 'it is a responsibility'.

The electoral incentives hypothesis is tested using a measure of the proportion of ethnic minorities in the constituency. Using a cut-off of 20 per cent in line with existing literature (Sobolewska 2013), the seats with this proportion of minorities or more are thought to be sufficiently ethnically diverse to offer incentives for representation of ethnic minority interests (the analyses were not sensitive to the cut off chosen).In this paper we are unable to offer any insights as to the extent of the influence of electoral incentives on substantive representative outcomes, but we have set out to test some of the theoretical possibilities around how this mechanism for representation may work, aside from the usually assumed electoral calculus. Specifically, we hypothesise that the ethnic make-up of electoral seats may influence the two intrinsic motivation attitudes. Of course, the electoral calculus on the part of the representatives (or in our case prospective representatives) may well dictate whom they choose to substantively represent and the kind of attitudes they express in public thus making them hard to study. However, because we use an anonymous postal survey, removing the incentive to express false attitudes for electoral gains, and minimising social desirability biases, without inducing interviewer effects, we are confident that the measures analysed capture intrinsic motivation; this allows us to test the possibility that (aside from any real electoral calculations) the ethnic make-up of a constituency may increase intrinsic motivation to represent.

\section{RESULTS AND DISCUSSION}

We start by considering our initial hypotheses using simple descriptive analysis, before we test them in multivariate regressions. Turning to H1 (Ethnic minority candidates have a sense of shared experience of ethnicity and race than white candidates) first, we present 
our results in Table 1 below. We find that ethnic minority candidates show higher levels of agreement with the statement designed to measure the sense of shared experience, with twice as many as their white peers agreeing that non-whites are held back by prejudice and discrimination. This strongly suggests that they are displaying shared experience with minority voters. However, all candidates regardless of ethnicity agree that non-whites are held back by more than 60 per cent. This is a particularly large proportion when compared to ethnic minority voters, for whom we only have reliable data from the 2010 Ethnic Minority British Election study. In this study only $45 \%$ of minority respondents expressed the sense of shared fate, although this did vary by ethnic group (Heath et al. 2013, p115). This again underlines that this item is a measure of a political attitude that serves as a mobilising factor among some minority voters (Dawson 1994), and clearly is more widespread among those minorities who are more politically engaged, which parliamentary candidates are clearly an example of.

\section{TABLE 1 HERE}

These high levels of agreement, especially among white candidates, are striking. While it is possible that it is a strongly self-policed issue, perceived as socially (and politically) desirable, thus social desirability bias may be responsible for this strong consensus, as indicated earlier this is unlikely to be an issue with an anonymous postal survey, unless these attitudes were internalised. Another possibility is that candidates for Parliament are more likely to be drawn from society's elite, and university educated (Lamprinakou et al. 2016). In this sample $77.5 \%$ of respondents, who answered the 
question $(n=1,798)$ attended university compared with $27 \%$ of the UK population ${ }^{6}$. Since education has been shown to correlate with lower levels of prejudice, it is likely that their racial attitudes will be more liberal (Storm, Sobolewska and Ford 2017) and thus more sensitive to issues of racial discrimination than the voters, even those voters who may experience discrimination directly. However, despite the seeming consensus on this issue among all candidates, ethnic minority candidates show a much greater agreement with this item, signalling a sense of shared experience, than white candidates, thus supporting H1.

Similarly, when we look at the candidates' sense of responsibility to represent ethnic minorities $\left(\mathrm{H}_{2}\right.$ : Ethnic minority candidates have greater sense that being of ethnic minority origin is a responsibility to represent minorities), we see that the intrinsic motivation to represent is again very high among minority candidates. Figure 1 shows that these candidates felt very strongly that ethnicity gave them a special responsibility to represent minority voters (skewness $-0.977 \mathrm{SE}=0.316$ ), corresponding with the findings in the US literature that black legislators are more intrinsically motivated to provide representation for their in-group (Swain 1993; Grose 20051 Broockman 2013). The vast majority of minority candidates, 63 per cent, agreed that their ethnicity presented a responsibility to represent minorities (points 6-10), and28per cent were at the most extreme end of agreement (points 9 and 10). However, 22per cent were closer to disagreeing (points 0-4), and as much as 9 per cent of minority candidates placed themselves on the extreme of disagreeing (point 0 ).

\footnotetext{
${ }^{6}$ Census 2011

http://webarchive.nationalarchives.gov.uk/20160105160709/http://www.ons.gov.uk/ons/re 1/census/2011-census-analysis/local-area-analysis-of-qualifications-across-england-andwales/sty-qualification-levels.html
} 


\section{FIGURE 1 HERE}

White candidates' responses to the same question were less skewed (skewness=0.293, $\mathrm{SE}=0.073$ ) and less polarised. The largest single grouping of white candidates, 16 per cent, responded at point 5 and only 29 per cent of white candidates, almost half that of ethnic minority candidates, placed themselves closer to the end of the scale agreeing that candidates from an ethnic minority had a responsibility to represent minorities (points 6-10). Minority candidates responded more positively to the notion of responsibility, $($ mean $=6.79)$ than white candidates $($ mean=4.9). Next, we turn to see if this slight polarisation, amongst ethnic minority candidates in particular, can be explained by party affiliation and the parties' differential approaches to ethnicity and its representation.

We hypothesised that party ideology can impact on the relationship between a candidates' ethnicity and their intrinsic motivation to represent (H3). In particular we expect that Labour and Liberal Democrats party candidates will score higher than candidates of other parties. Table 2 demonstrates that as hypothesised there is considerable variation by party in candidates' support for both items. Firstly, looking at the perception that prejudice holds non-white people back, even though ethnic minority candidates are always more supportive of the notion that discrimination holds non-white people back, whatever the party, the levels of support and the gap between ethnic minority and white candidates vary substantially between parties.

TABLE 2 HERE 
The difference between ethnic minority and white candidates is most stark within right-wing parties, and not left-leaning and liberal ones. Labour minority candidates agreed 92 per cent that discrimination holds non-white people back, and their white peers followed closely with 88 per cent agreement. Minority Liberal Democrats had 90 per cent agreement and their white counterparts were not far behind on 73 per cent. In contrast, Conservative ethnic minority candidates had only a 50 per cent rate of agreement, even below UKIP minority candidates ( 75 per cent). The gap between minorities and white Conservative candidates was 26 per cent (beating Labours' gap of 4 and Liberal Democrat's gap of 17). However, amongst UKIP candidates the polarisation by ethnicity is most stark, with a 62 percent gap in perceptions of white and minority candidates.

Looking at responsibility to represent, party affiliation matters again, but to a smaller degree. Support for responsibility to represent is highest amongst Labour candidates, followed by Liberal Democrats, Conservative and finally UKIP candidates scoring around 1 point lower than Labour candidates on average, and this difference is significant. Ethnicity is also important here and again the minority candidates of all parties are more in agreement with the two items measuring intrinsic motivation. Support for responsibility to represent amongst ethnic minority candidates of all parties is above the neutral value (5), but unlike the previous item, with the exception of UKIP minority candidates (mean 5.4), ethnicity seems to trump party with the other three parties' showing only very small differences in attitudes. Labour, Conservative and Liberal Democrat minority candidates in general are all motivated to represent their minority voters (means of 7, 6.83 and 6.53 respectively). Again, this may point to the fact that the sense of shared experience is a very much political (and politicised) attitude (Dawson 1994) and the sense of responsibility does not lend itself to the influences of party ideology in the same fashion. 
As hypothesised, there is a considerable disparity between parties on both measures of intrinsic motivation. We argued this was due to the very different responses of British political parties to post-war racial and ethnic diversity and the model of incorporation they advocated (and subsequently which political appeal they chose to extend to the potential new voters). However, this difference is also most likely reflected in party choice of minority voters themselves, with the sense of the shared experience being an important predictor of party choice (Sanders et al 2013). With the growing (albeit slowly) proportion of Indian voters choosing to support the Conservative party and as they do not have a strong sense of shared fate (Heath et al 2013) we see that that voters also divide on this issue and thus parties may well be offering a good level of representation on this issue. An interesting result of this analysis however is that Liberal Democrats fall between Labour and Conservatives on the two different measures: while they are much closer to Labour on the perceptions on the role of prejudice, they are closer to Conservatives when it comes to responsibility to represent.

To make a start on testing $\mathrm{H} 4.1$ that both attitudes will be more positive 'among candidates contesting electoral districts with strong ethnic minority presence' table 3 presents some descriptive statistics of candidates' responses to both attitudes by their ethnicity and ethnic density of the constituency they are contesting. We include a measure of the proportion of ethnic minority residents in the constituency ${ }^{7}$, in order to identify electoral districts where minority voters are sufficiently concentrated to influence the positions of candidates contesting those districts.

${ }^{7}$ Data taken from 2011 Census, ethnic density calculated as the number of non-white usual residents as a proportion of all usual residents in the constituency. 


\section{TABLE 3 HERE}

Candidates with a greater proportion of ethnic minority constituents respond slightly more positively to the question on prejudice holding non-white people back, with 6 per cent more agreement than among those candidates standing in more ethnically white seats (H4.1). However, when we look at the ethnicity of candidates within these two types of seat, ethnicity again is the dominant influence (H4.2). While we already know that ethnic minority candidates in both groups agree more strongly than white candidates with the statement that ethnic minorities are held back by prejudice and discrimination, the demographic make-up of the seat seems to influence their opinion in a way that is not the case for their white counterparts. This is especially true with extreme agreement with the shared experience statement, as the percentage of candidates strongly agreeing with the statement goes up from 35 per cent in less ethnically diverse seats to 53 per cent in more diverse constituencies.

Turning to responsibility to represent, those in ethnically diverse seats also show a slightly more positive response...Again the ethnic minority candidates in both groups agree more strongly with their responsibility to represent than their white counterparts, but the make- of the seat similarly seems to impact on their views only. White candidates by contrast are unmoved by the demographic make-up of their seat.

So far, all hypotheses receive some tentative support. However, to disentangle the relative impact of ethnicity, party and ethnic make-up of constituencies, we turn to a multivariate analysis. As the two intrinsic mechanism items were measured on an ordinal scale, the associations are examined using ordered logistic regression. The Odds Ratios were calculated by exponentiating the Parameter Estimates and the significance values were taken from the parameter estimates output. The proportional odds assumption was 
tested using the test of parallel lines. The correlation was measured using Nagelkerke's $r^{2}$. Table 4 shows the odds ratios for moving one point on a five point scale, from Strongly Disagree to Strongly Agree, onthe prejudice holds non-white people back item; and shows the odds ratios for moving one point on al 11-point scale (0-10) from disagreeing to agreeing with the responsibility to represent item.

\section{TABLE 4 HERE}

Using a step wise approach, we first entered ethnicity of the candidates alone, to assess whetheer introducing the other variables will diminish the size and importance of ethnicity. However, we see from the second column in both regression models, that the effect of ethnicity survives controlling for party and ethnic composition in the multivariate model. Other predictors behave very much as we expected them to based on oour descriptive analyses. Candidates from right wing parties are much less likely to agree than those in left leaning ones, with the odds ratios below lalthough the effects are much smaller. Being a right wing party candidate was coded as UKIP and Conservative, but these results are robust to treating these two parties separately (as we see in Appendix). However, the demographic make-up of the constituency is not statistically significant, perhaps reflecting the fact that we saw in Table 3 that its effects were confined to minority candidates only.

Interaction effects were included looking at whether party moderates the effect of ethnicity of candidates. There is a strong and significant positive interaction with party and minority origin, for the 'non-white people are held back by prejudice' item, suggesting as we saw in the bivariate analysis earlier that minority candidates of right leaning parties still display a sense of shared experience. For responsibility to represent the interaction between candidates' ethnicity and right-wing party has no significant 
effect suggesting no meaningful impact of ethnicity on this item. For shared experience the fact that the main effect of ethnicity is only slightly diminished by the inclusion of interaction with party suggests that the ethnic differences among left wing parties remain significant too. The party main effect also remains unchanged. Thus, while party has an effect on both white and minority candidates, ethnicity remains the main influence on the perception of shared experience for minority candidates.

There was mixed support for $\mathrm{H} 4$, that candidates contesting ethnically diverse constituencies will feel more intrinsically motivated to represent them with Table 3 suggesting that it might be the case for minority candidates only. Turning to multivariate models, we see that where the non-white population makes up $20 \%$ or more of the seat, there is no statistically significant relationship for all candidates. However, considering the interactions between ethnicity of candidates and the ethnic density of seats confirms what we saw in Table 3, that ethnic minority candidates are more sensitive than white candidates to an ethnic make-up of the districts they contest. Partly, the strong positive correlation seems to account for some of the effect of ethnicity of the candidate in the first place (especially for the sense of responsibility to represent), suggesting that minority candidates may still be more often encountered in ethnically diverse seats (Sobolewska 2013). The fact that seeking to win in an ethnically diverse constituency is linked to a greater sense of shared experience and responsibility to represent among minority candidates, but not among their white counterparts suggests that H4 only holds for minority candidates. Thus, for minority candidates we can speak of internalised motivation over and above any rational choice calculations that may be taking place (and for which we cannot test). 


\section{CONCLUSION}

Using survey data from ethnic minority and white candidates at the 2015 UK General Election this paper empirically examines three of the most often posited theoretical mechanisms for why we should expect a link between descriptive and substantive representation of ethnic minorities. The three mechanisms we were able to elaborate on are (1) ethnic minority candidates and voters had a unique sense of linked-fate as a nonwhite minority group (intrinsic), (2) ethnic minority candidates felt a responsibility represent ethnic minority interests (intrinsic), (3) ethnic minority candidates predominantly stood for election in ethnic minority-majority districts and thus it was in their electoral interest to attend to minority representation (extrinsic). Although because of the limitations of our data we were not able to test directly for the presence of extrinsic motivation, we tested the possibility that ethnic minority-majority districts influence levels of intrinsic motivations to represent, thus presenting more than a simple extrinsic cost-benefit transaction on the part of (prospective) representatives. We also tested the possibility that ethnic minority, and indeed white candidates of different parties will have different, ideologically-motivated approaches to ethnic representation.

This study used direct measurements of both of the intrinsic motivations. These are able to capture both a sense of shared experience, measured by a sense that ethnic minorities are held back and a responsibility to represent, measured by agreement that being an ethnic minority candidate confers a special responsibility to represent ethnic minorities. Using these direct measurements allows us to pin point the motivation mechanism, rather than inferring the mechanisms from outcomes. This allows us to test, distinct from each other, both sense of shared experience and responsibility to represent. However, the limitation of our lack of data on representational outcomes has been that 
apart from looking into how a seemingly extrinsic motivation can be internalised, we were unable to test the effects of extrinsic motivation directly.

We found that both intrinsic mechanisms for why ethnic minority candidates would want, or be able, to represent ethnic minorities in parliament received empirical support. Interestingly, we found that in fact white candidates of all mainstream parties also shared the perception that racial prejudice holds minorities back. This shared perspective between white and ethnic minority candidates may help explain why the gap in levels of substantive representation from minority and white Parliamentarians in Britain has previously been found to be very small (Saalfeld and Bischof 2012). However, in the case of white candidates, it is difficult to interpret and may be a reflection of the sense that denying prejudice and discrimination may be politically incorrect, or it may reflect the general liberalism of political elites. The fact however that on both measures minority candidates agreed with the items more than their white counterparts signals that they felt a sense of shared experience with other non-white people in Britain, and a strong sense of responsibility to represent ethnic minority voters.

We found persuasive evidence of the impact of party ideology. Candidates from parties of the left were more likely to support the notion that members of ethnic minority communities share the experience of being held back by prejudice and discrimination, whilst the reverse was true of candidates from parties of the right. We also found that the sense of responsibility also varied by party, but to a lesser extent.

Finally, we found our hypothesis that ethnic make-up of electoral districts increases intrinsic motivation to represent rather than presents a simple case of calculated self-interest from the representatives, only received support for ethnic minority candidates. For them, seeking to represent an ethnically diverse seat increases their sense of shared fate and responsibility to represent minority voters. For the white candidates, 
no such attitudinal change takes place suggesting that where effects of the demographics of districts were found to affect the representatives' behaviour (Saalfed and Bishof 2013), it may well be a result of purely electoral calculus.

The most important contribution this paper makes is the more detailed understanding of the intrinsic motivation behind descriptive representatives' willingness and ability to represent. The innovation is in distinguishing the two separate, but usually poorly differentiated mechanisms: shared experience and explicit (conscious) motivation to represent. Our sense that these two should be conceptually distinct is confirmed by our empirical finding that they had a different relationship with predictor variables such as party affiliation and ethnic make-up of the electoral district. Our paper also indicates the complex nature of what is often assumed to be an extrinsic motivation to represent, linked to direct electoral incentives. Given the relationship between ethnic diversity of the constituency and the intrinsic measures of motivation, it is possible that apart from the obvious electoral advantages of representing ethnic minority voters well when they form a significant proportion of one's electorates, one other advantage that minority candidates who stand in ethnically diverse seats have, is a greater opportunity to learn and appreciate the role that racial discrimination plays in their minority voters' lives.

It is significant that although the white candidates in our survey largely agreed that ethnic minorities in Britain share an experience of being held back by racial discrimination and prejudice, for them this was both an ideological point of view (influenced by their political party affiliation). As it was not sensitive to being exposed to electoral competition in an ethnically diverse district. This suggests that ethnicity trumps all the other influences for ethnic minority candidates and supports the existence of a direct link between descriptive and substantive representation for candidates of all 
parties, and especially those with ethnic minority voters. These empirical results strongly support the normative arguments for increased descriptive representation.

These findings push forward the agenda of studying representation significantly, but they do suffer from a couple of limitations that need to be resolved in future research. Firstly, the difficulty of studying extrinsic motivation with attitudinal data, as we have done here, and intrinsic motivation with outcome data, as has been done elsewhere (Brookman 2013) is clear. Future studies of motivation to represent should attempt to study attitudes and outcomes together. Secondly, while our data include incumbents, and not just parliamentary candidates, we do not have sufficient numbers of ethnic minority MPs to investigate whether motivation operates differently for prospective and current representatives. It is possible that candidates are more optimistic about their ability to represent before they encounter the many limitations the role of a representative bring. Perhaps the incumbents are less beholden to their party ideology as they no longer rely to the same extent on their parties' to get them elected. As the numbers of elected minority representatives increase, these questions might be a fruitful areas of research in the future.

\section{Acknowledgments}

This work was supported by the Economic and Social Research Council [grant number ES/L016508/1; ES/K002198/1]. We thank Thomas Saalfeld and David Broockman for their comments on the earlier drafts of this paper. We would also like to thank all of the respondents of Representative Audit of Britain, and the amazing team who conducted this survey.

\section{Disclosure statement}

No potential conflict of interest was reported by the authors. 


\section{Notes on contributors}

Maria Sobolewska is a Senior Lecturer in Politics at Manchester University. She works on the politics of diversity and its impact on public opinion and voting behaviour. She published on representation, political attitudes of ethnic minorities in Britain and immigrant integration. She is the principal investigator of the ESRC funded project: The 'Brexit Referendum' and Identity Politics in Britain: Social Cleavages, Party Competition and the Future of Immigration and Integration Policy.

Rebecca McKee is a Research Associate at the Constitution Unit, University College London. She previously held a Research Associate position at the University of Manchester within the Centre on the Dynamics of Ethnicity (CoDE). She completed her $\mathrm{PhD}$ at the University of Manchester in 2017. Her research centres on the substantive representation of ethnic minorities as well as UK parliamentary diversity and reform. Rebecca is the Editorial Assistant of the Journal of Elections Public Opinions and Parties since 2015.

Rosie Campbell is a Professor of Politics at Birkbeck University of London. She has recently written on what voters want from their parliamentary candidates, attitudes to MPs' roles, the politics of diversity and gender and voting behaviour. She is the principal investigator of the ESRC funded Representative Audit of Britain, which surveyed all candidates standing in the 2015 and 2017 British General Elections.

\section{Orchid numbers of contributors}

Maria Sobolewska https://orcid.org/0000-0001-9858-5091

Rebecca Mckee https://orcid.org/0000-0002-3221-0809

Rosie Campbell https://orcid.org/0000-0003-2035-9865 


\section{REFERENCES}

Afriyie, Adam (2010). Adam Afriyie MP: Positive discrimination has no place in the selection of candidates for roles in politics, business or even the pulpit. In Conservative Home.

Bird, Karen., Vincent Tiberj, Thomas Saalfeld, Laure Michan, Jean Tillie, Dirk Jacobs, Pascal Dewit, Nazem Tahvilzadeh, Johannes Bergh, Tor Bjørklund, Flemming Mikkelsen and Andreas Wüst. (2010). 'Party choices among immigrants and visible minorities in comparative perspective ', in Karen Bird, Thomas Saalfeld and Andreas Wüst (eds.), The political representation of immigrants and minorities: Voters, parties and parliaments in liberal democracies. New York: Routledge, 66-106.

Bratton, Kathleen A., and Kerry L. Haynie (1999). 'Agenda Setting and Legislative Success in State Legislatures: The Effects of Gender and Race ', The Journal of Politics, 61:3, 658-679.

Broockman, David E (2013). 'Black Politicians Are More Intrinsically Motivated to Advance Blacks' Interests: A Field Experiment Manipulating Political Incentives ', American Political Science Review, 57:3, 521-536.

Burden, Barry C (2007). Personal Roots of Representation. Princeton, NJ: Princeton University Press.

Butler, Daniel M., and David E. Broockman (2011). 'Do Politicians Racially Discriminate Against Constituents? A Field Experiment on State Legislators', American Journal of Political Science, 55:3, 463-477. 
Casellas, Jason P., and David L. Leal (2010). 'Minority representation in the US Congress', in Karen Bird, Thomas Saalfeld and Andreas Wüst (eds.), The political representation of immigrants and minorities: Voters, parties and parliaments in liberal democracies. New York: Routledge,

Celis, Karen (2012). 'On Substantive Representation, Diversity, and Responsiveness ', Politics \& Gender, 8:4, 524-529.

Chaney, Paul (2015). 'Manifesto Discourse and the Substantive Representation of Ethnic Minorities: Analysis of UK State-Wide and Meso Elecion, 1964-2011', Parliamentary Affairs, 68:1, 154-181.

Dawson, Michael C (1994). Behind the mule: Race and class in African-American politics. Princeton, NJ: Princeton University Press.

Dovi, Suzanne (2002). 'Preferable Descriptive Representatives: Will Just Any Women, Black or Latino Do?', American Political Science Review, 96:4, 729-743.

Ford, Robert., Matthew J. Goodwin and David Cutts (2012). 'Strategic Eurosceptics and polite xenophobes: Support for the United Kingdom Independence Party (UKIP) in the 2009 European Parliament elections', European Journal of Political Research, 51:2, $204-234$.

Franklin, M N., and P Norton (1993). 'Questions and Members ', in M N Franklin and P Norton (eds.), Parliamentary Questions. Oxford: Clarendon Press, 104-122.

Garbaye, Romain (2008). 'Birmingham, 1980s-2001: Inner-City Labour Politics and Pluri-Ethnic Government ', in (eds.), Getting into Local Power. Blackwell Publishing Ltd, 92-143. 
Gay, Claudine., and Katherine Tate (1998). 'Doubly bound: The impact of gender and race on the politics of Black women ', Political Psychology, 19:1, 169-184.

Gay, Claudine (2004). 'Putting Race in Context: Identifying the Environmental Determinants of Black Racial Attitudes', The American Political Science Review, 98:4, 547-562.

Grose, Christian R (2005). 'Disentangling Constituency and Legislator Effects in Legislative Representation: Black Legislators or Black Districts?', Social Science Quarterly, 86:2, 427-443.

Heath, Anthony F., Stephen D. Fisher, Gemma Rosenblatt, David Sanders and Maria Sobolewska, (2013). The political integration of ethnic minorities in Britain. Oxford: Oxford University Press.

Junn, Jane., and Natalie Masuoka (2008). 'Asian American identity: Shared racial status and political context', Perspectives on Politics, 6:4, 72940.

Kittilson, Miki C., and Katherine Tate (2004). 'Politics Parties, Minorities, and Elected Office; Comparing Opportunities for Inclusion in the United States and Britain', in Christina Wolbrecht and Rodney E. Hero (eds.), The Politics of Democratic Inclusion. Philadelphia, PA: Temple University, 163-185.

Lamprinakou, Chrysa., Marco Morucci, Rosie Campbell and Jennifer van Heerde-Hudson (2016). 'All Change in the House? The Profile of Candidates and MPs in the 2015 British General Election', Parliamentary Affairs, 70:2, 207-232. 
Lublin, D (1999). The paradox of representation: Racial gerrymandering and minority interests in Congress. Princeton, NJ: Princeton University Press.

Mansbridge, Jane (1999). 'Should Blacks Represent Blacks and Women Represent Women? A Contingent 'Yes", The Journal of Politics, 61:3, 628-657.

Mansbridge, Jane (2003). 'Rethinking representation ', American Political Science Review, 97:4, 515-28.

Meier, Kenneth J., Eric Gonzalez Juenke, Robert D. Wrinkle and J. L. Polinard (2005). 'Structural Choices and Representational Biases: The Post-Election Color of Representation ', American Journal of Political Science, 49:4, 758-768.

Miller, Arthur H., Patricia Gurin, Gerald Gurin and Oksana Malanchuk (1981). 'Group Consciousness and Political Participation', American Journal of Political Science, 25:3, 494-511.

Miller, Warren E., and Donald W. Stokes (1963). 'Constituency Influence in Congress ', American Political Science Review, 57:1, 45-57.

Minta, Michael D (2009). 'Legislative oversight and the substantive representation of Black and Latino interests in Congress', Legislative Studies Quarterly, 34:2, 193-218.

Norris, P (2004). Electoral Engineering: Voting rules and political behaviour. Cambridge: Cambridge University Press. 
Norris, Pippa., Andrew Geddes and Joni Lovenduski (1992). 'Race and parliamentary representation', British Elections and Parties Yearbook, $2: 1,92-110$

Preuhs, Robert R (2006). 'The conditional effects of minority descriptive representation: Black legislators and policy influence in the American states', Journal of Politics, 68:3, 585-599.

Saalfeld, Thomas., and Daniel Bischof (2012). 'Minority-Ethnic MPs and the Substantive Representation of Minority Interests in the House of Commons, 2005-2011', Parliamentary Affairs, 66:2, 305-328.

Saalfeld, Thomas., and Kalliopi Kyriakopoulou (2010). 'Presence and Behaviour; Black and minority ethnic MPs in the British House of Commons', in Karen Bird, Thomas Saalfeld and Andreas Wüst (eds.), The political representation of immigrants and minorities: Voters, parties and parliaments in liberal democracies. New York: Routledge, 230-49.

Saalfeld, Thomas., Andreas Wüst and Constanza Sanhueza, (2011). Immigrant MPs in Britain, France and Germany: Roles and Activities. Sao Paulo: February 2011.

Saward, Michael (2006). 'The Representative Claim', Contemporary Political Theory, 5:3, 297-318.

Saward, Michael (2010). The Representative Claim. Oxford: Oxford University Press.

Sobolewska, Maria (2013). 'Party Strategies and the Descriptive Representation of Ethnic Minorities: The 2010 British General Election', West European Politics, 36:3, 615-633. 
Storm, Ingrid,. Maria Sobolewska and Robert Ford (2017) 'Is ethnic prejudice declining in Britain? Change in social distance attitudes among ethnic majority and minority Britons.' The British Journal of Sociology, 68:3, 410-434.

Swain, Carol M (1993). Black Faces, Black Interests. The Representation of African Americans in Congress. Cambridge: Harvard University Press.

Tate, Katherine (2003). Black faces in the mirror: African Americans and their representatives in the US Congress. Princeton, NJ: Princeton University Press.

van Heerde-Hudson, J., and R Campbell (2015). Parliamentary Candidates UK Dataset (v.1). http://www.parliamentarycandidates.org/.

Welch, Susan., and John R Hibbing (1984). 'Hispanic Representation in the U.S. Congress', Social Science Quarterly, 65:2, 328-35.

Whitby, Kenny J (1997). The Color of Representation; Congressional Behavior and Black Interests. Ann Arbor: University of Michigan Press. 
Table 1 Responses to "non-white people are held back by prejudice and discrimination"

(shared experience) by ethnicity of candidates, category percentages.

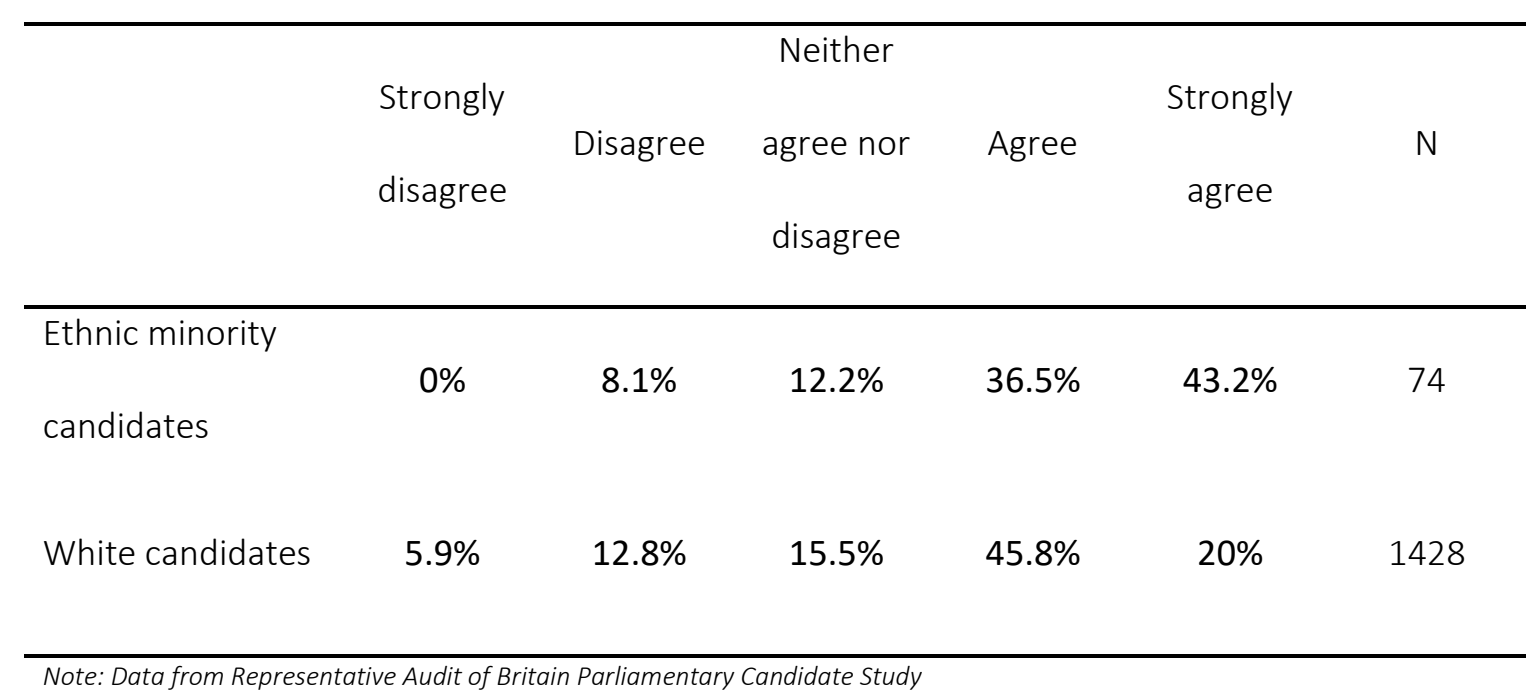




\begin{tabular}{|c|c|c|c|c|c|c|}
\hline & $\begin{array}{c}\text { Disagree/Strong } \\
\text { ly disagree }\end{array}$ & $\begin{array}{l}\text { Neither agree } \\
\text { nor disagree }\end{array}$ & $\begin{array}{c}\text { Agree/Strong } \\
\text { ly agree }\end{array}$ & $\mathrm{n}$ & $\begin{array}{l}\text { Mean score on } 0 \text { - } \\
10 \text { scale agreeing it } \\
\text { is a responsibility }\end{array}$ & $\mathrm{n}$ \\
\hline \multicolumn{7}{|l|}{$\underline{\text { Labour }}$} \\
\hline Minority candidates & $0.0 \%$ & $7.7 \%$ & $92.4 \%$ & 13 & 7.13 & 8 \\
\hline White candidates & $3.5 \%$ & $8.7 \%$ & $87.9 \%$ & 264 & 5.54 & 208 \\
\hline All candidates & $3.2 \%$ & $8.7 \%$ & $88.0 \%$ & 277 & 5.6 & 216 \\
\hline \multicolumn{7}{|l|}{ Lib-Dem ${ }^{*+\dagger}$} \\
\hline Minority candidates & $0.0 \%$ & $10.0 \%$ & $90.0 \%$ & 20 & 6.53 & 17 \\
\hline White candidates & $8.7 \%$ & $18.4 \%$ & $72.9 \%$ & 369 & 4.74 & 303 \\
\hline All candidates & $8.3 \%$ & $18.0 \%$ & $73.8 \%$ & 389 & 4.84 & 320 \\
\hline \multicolumn{7}{|l|}{ Conservative $^{* \dagger}$} \\
\hline Minority candidates & $31.3 \%$ & $18.8 \%$ & $50.1 \%$ & 16 & 6.83 & 12 \\
\hline White candidates & $49.3 \%$ & $25.9 \%$ & $24.7 \%$ & 158 & 4.18 & 116 \\
\hline All candidates & $47.7 \%$ & $25.3 \%$ & $27.0 \%$ & 174 & 4.43 & 128 \\
\hline UKIP* & & & & & & \\
\hline
\end{tabular}


Minority candidates

$8.3 \%$

$66.2 \%$

$63.1 \%$

$21.1 \%$

$20.9 \%$

$16.0 \%$

$12.7 \%$
$75.0 \%$

225

213

12

Note: Data source see Table 1

Shared experience Chi square* Significant $p=0.001$

Responsibility One Way Anova ${ }^{\dagger}$ Significant $p=0.001{ }^{+\dagger}{ }^{+}$Significant $p=0.05$
3.74 
Table 3 Percentage agreeing that non-whites are held back by discrimination (shared experience) and mean

(0-10) agreement that ethnic minorities have a responsibility to represent minorities (responsibility to

represent); by ethnic density of constituency.

\begin{tabular}{|c|c|c|c|c|c|c|c|c|}
\hline & \multicolumn{6}{|c|}{ Shared experience } & \multicolumn{2}{|l|}{ Responsibility to represent } \\
\hline & $\begin{array}{l}\text { Strongly } \\
\text { disagree }\end{array}$ & Disagree & $\begin{array}{l}\text { Neither } \\
\text { agree } \\
\text { nor } \\
\text { disagree }\end{array}$ & Agree & $\begin{array}{l}\text { Strongly } \\
\text { agree }\end{array}$ & $n$ & $\begin{array}{l}\text { Mean score on 0-10 scale } \\
\text { agreeing it is a } \\
\text { responsibility }\end{array}$ & $n$ \\
\hline $\begin{array}{l}\text { High ethnic } \\
\text { density**† }\end{array}$ & & & & & & & & \\
\hline All candidates & $6.6 \%$ & $13.6 \%$ & $13.6 \%$ & $40.1 \%$ & $26.1 \%$ & 272 & 5.17 & 212 \\
\hline $\begin{array}{c}\text { Minority } \\
\text { candidates }\end{array}$ & $0 \%$ & $9.4 \%$ & $6.3 \%$ & $31.3 \%$ & $53.1 \%$ & 32 & 7.36 & 28 \\
\hline
\end{tabular}




\begin{tabular}{|c|c|c|c|c|c|c|c|c|}
\hline $\begin{array}{l}\text { White } \\
\text { candidates }\end{array}$ & $7.5 \%$ & $14.2 \%$ & $14.6 \%$ & $41.3 \%$ & $22.5 \%$ & 240 & 4.84 & 184 \\
\hline $\begin{array}{l}\text { Low ethnic } \\
\text { density }{ }^{\dagger \dagger}\end{array}$ & & & & & & & & \\
\hline All candidates & $5.4 \%$ & $12.4 \%$ & $15.7 \%$ & $46.5 \%$ & $20.1 \%$ & 1230 & 4.96 & 981 \\
\hline $\begin{array}{c}\text { Minority } \\
\text { candidates }\end{array}$ & $0 \%$ & $7.1 \%$ & $16.7 \%$ & $40.5 \%$ & $35.7 \%$ & 42 & 6.06 & 32 \\
\hline candidates & $5.6 \%$ & $12.5 \%$ & $15.7 \%$ & $46.7 \%$ & $19.5 \%$ & 1188 & 4.92 & 949 \\
\hline
\end{tabular}

Data see table 1

Ethnic density calculated from the 2011 census

Shared experience Chi square * Significant $p=0.001 ;{ }^{* *}$ Significant $p=0.01$

Responsibility One Way Anova ${ }^{\dagger}$ Significant $p=0.001 ;{ }^{+\dagger}$ Significant $p=0.05$ 
Table 4 Odds Ratio of agreeing that non-whites are held back by discrimination (shared experience) and ethnic minorities have a responsibility to represent minorities; calculated from ordinal logistic regression

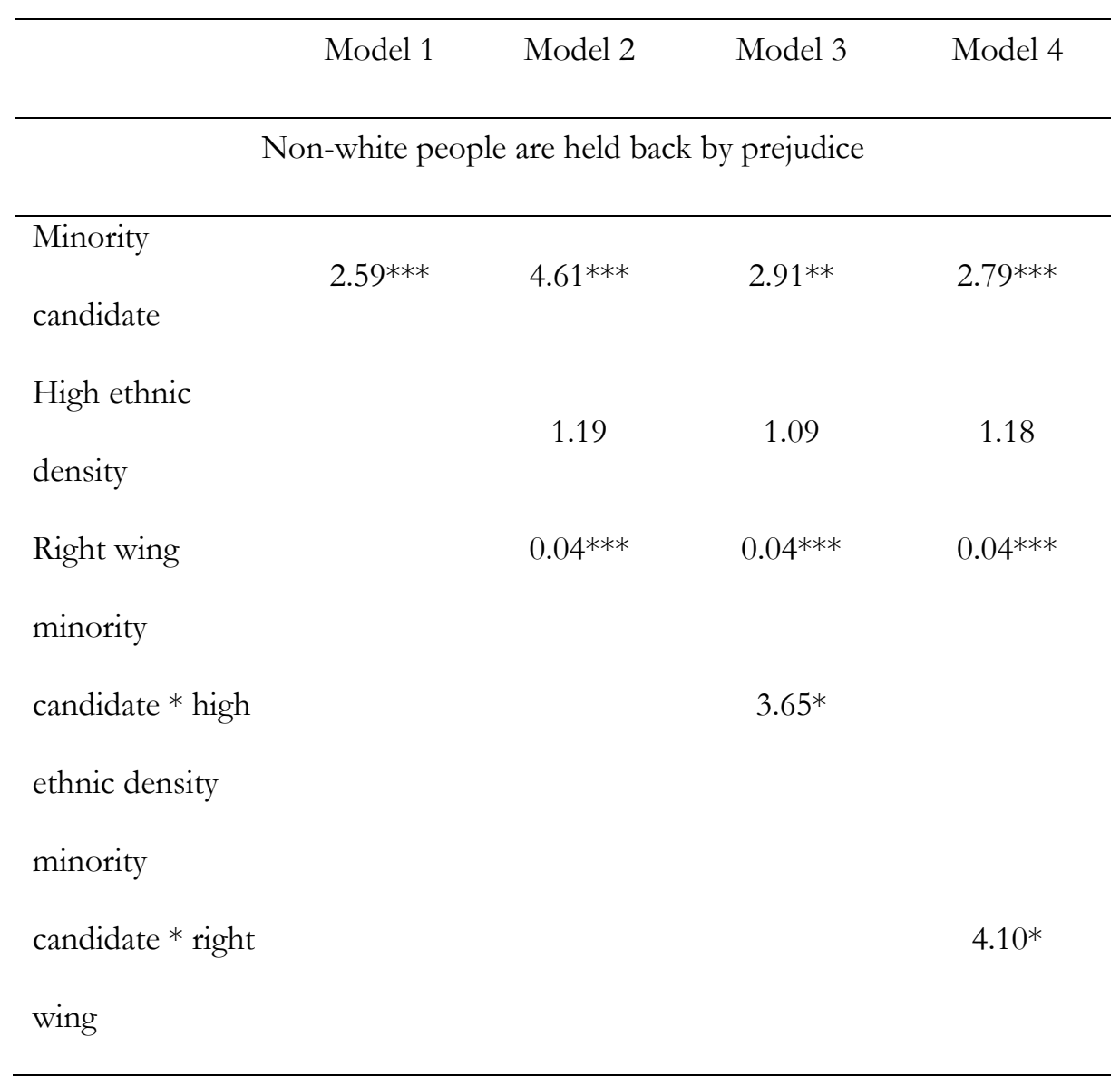




\begin{tabular}{|c|c|c|c|c|}
\hline Nagelkerke $\mathrm{r}^{2}$ & 0.01 & 0.11 & 0.11 & 0.11 \\
\hline $\mathrm{n}$ & 1502 & 1502 & 1502 & 1502 \\
\hline \multicolumn{5}{|c|}{ Responsibility to represent } \\
\hline $\begin{array}{l}\text { Minority } \\
\text { candidate }\end{array}$ & $4.39 * * *$ & $3.95^{* * *}$ & $2.23^{*}$ & $3.66^{* * *}$ \\
\hline $\begin{array}{l}\text { High ethnic } \\
\text { density }\end{array}$ & & 1.10 & 0.98 & 1.09 \\
\hline $\begin{array}{l}\text { Right wing } \\
\text { minority }\end{array}$ & & $0.44 * *$ & $0.42^{* *}$ & $0.42 * *$ \\
\hline $\begin{array}{l}\text { candidate * high } \\
\text { ethnic density }\end{array}$ & & & $3.97 * *$ & \\
\hline minority & & & & \\
\hline $\begin{array}{l}\text { candidate * right } \\
\text { wing }\end{array}$ & & & & 1.28 \\
\hline Nagelkerke $\mathrm{r}^{2}$ & 0.02 & 0.06 & 0.07 & 0.06 \\
\hline $\mathrm{n}$ & 1193 & 1193 & 1193 & 1193 \\
\hline
\end{tabular}


Appendix 1

Table 4.1 Odds Ratio of agreeing that non-whites are held back by discrimination (shared experience) and ethnic minorities have a responsibility to represent minorities; calculated from ordinal logistic regression

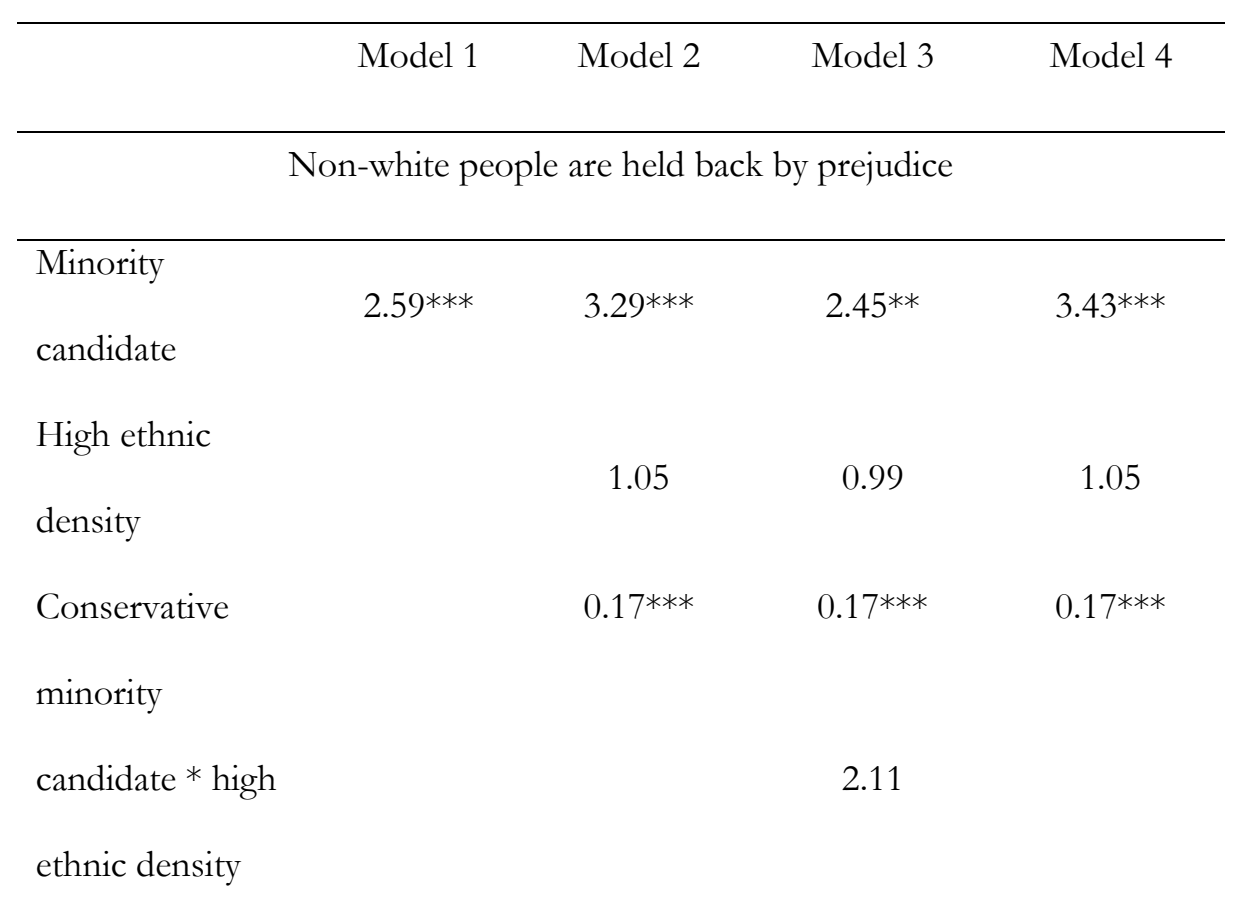


minority

candidate $*$

conservative

\begin{tabular}{lcccc}
\hline${\text { Nagelkerke } \mathrm{r}^{2}}$ & 0.012 & 0.111 & 0.113 & 0.111 \\
$\mathrm{n}$ & 1502 & 1502 & 1502 & 1502 \\
\hline
\end{tabular}

Responsibility to represent

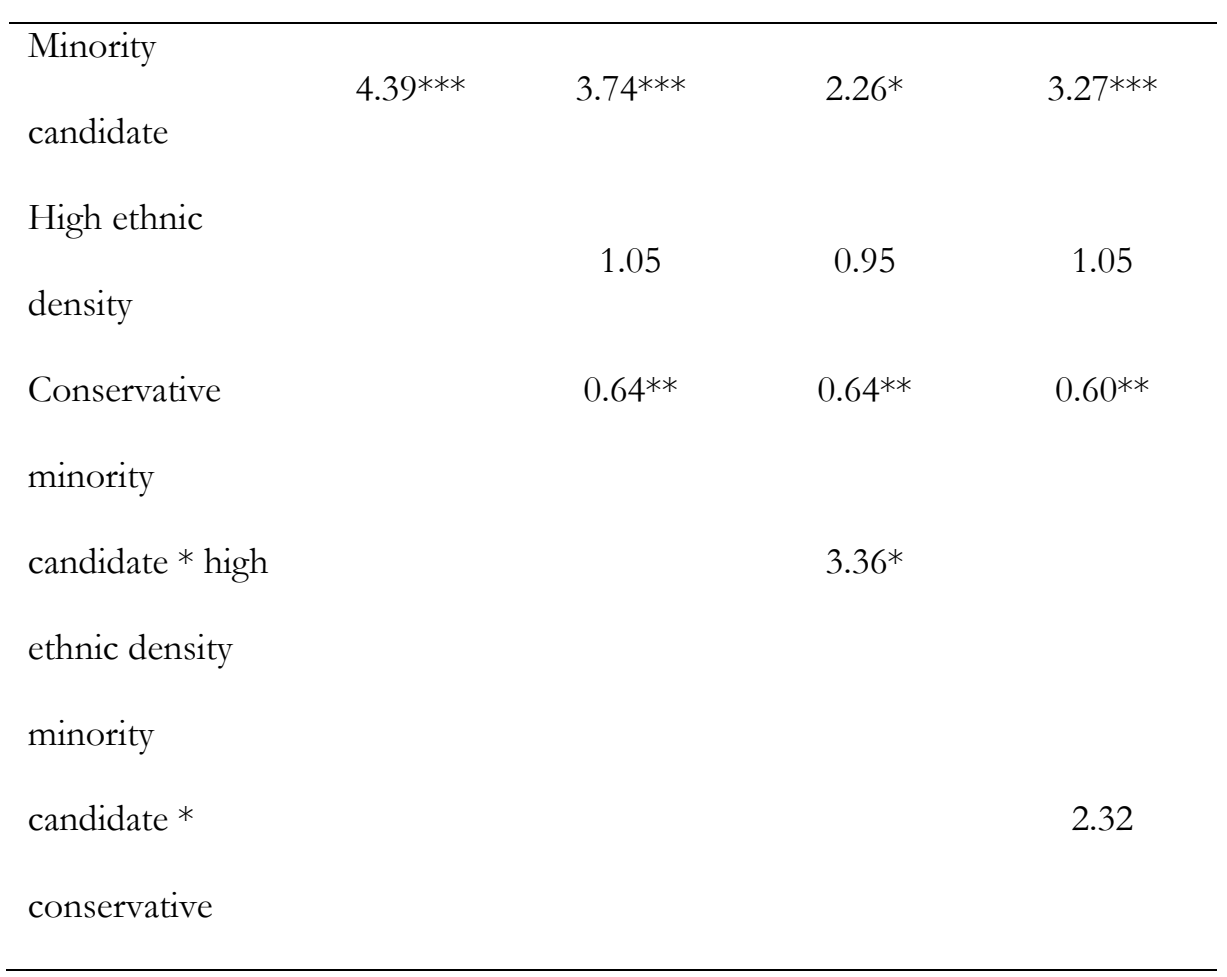




\begin{tabular}{lrrrr}
\hline${\text { Nagelkerke } \mathrm{r}^{2}}$ & 0.027 & 0.03 & 0.035 & 0.031 \\
$\mathrm{n}$ & 1193 & 1193 & 1193 & 1193 \\
\hline
\end{tabular}

Note: ${ }^{*} p<0.05,{ }^{* *} p<0.01,{ }^{* * *} p<0.00$ 
Figure 1

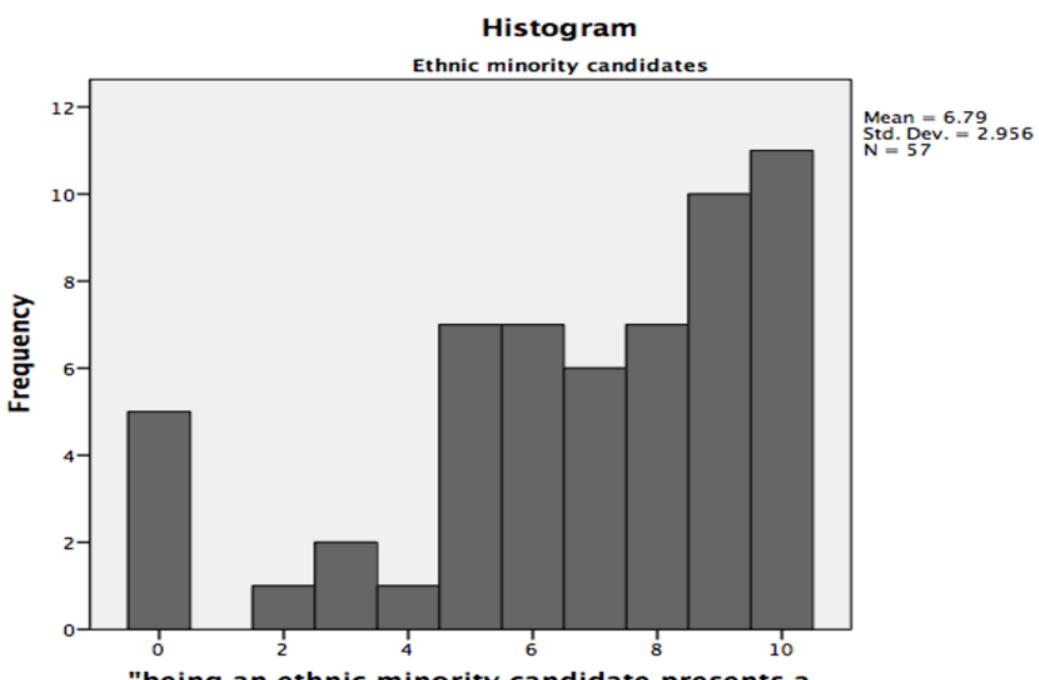

"being an ethnic minority candidate presents a responsibility to represent minorities"

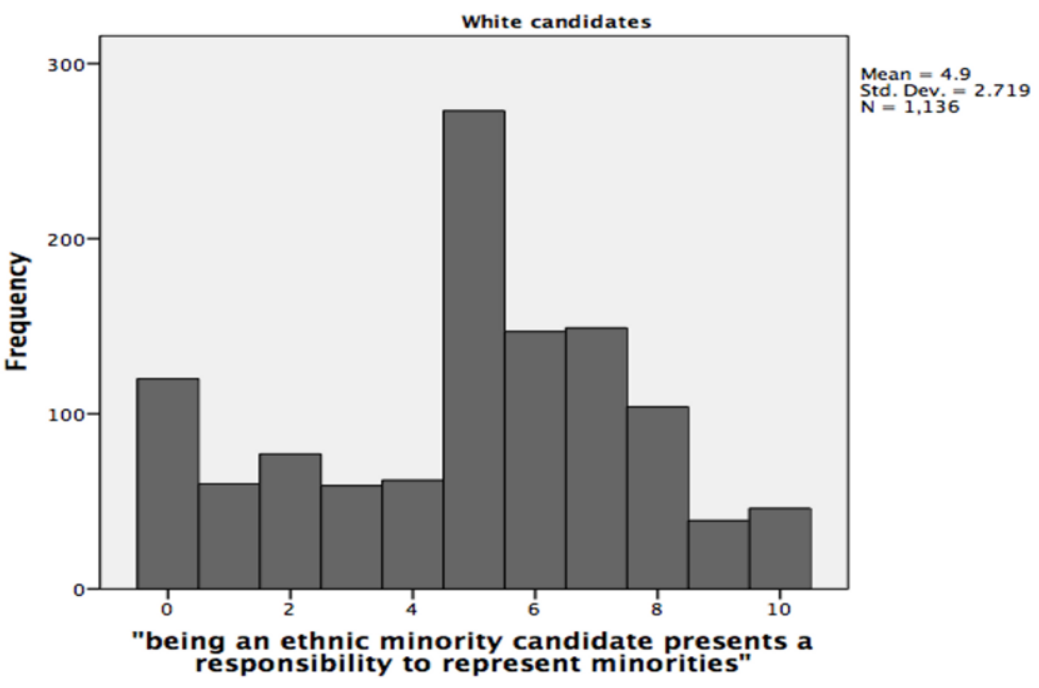

Figure 1 Frequency agreeing to the statement "being an ethnic minority candidate presents a responsibility to represent minorities" all candidates, histogram.

Note: Ethnic minority (Skewness $=-0.977, \mathrm{SE}=0.316$, Kurtosis $=0.246$

, $\mathrm{SE}=0.623$ ); White (Skewness $-0.293, \mathrm{SE}=0.073$, Kurtosis $=-0.671, \mathrm{SE}=0.145$ ) 